\title{
Фізична терапія пацієнтів з посттравматичними контрактурами ліктьового суглоба
}

\author{
Борис Пустовойт \\ Святослава Пашкевич \\ Ольга Без'язична \\ Тетяна Парфанюк
}

Харківська державна академія фізичної культури, Харків, Україна

Мета: розробити та обгрунтувати сучасну програму фізичної терапії осіб з посттравматичними контрактурами ліктьового суглоба у пізньому післяопераційному періоді з використанням оціночних шкал для окремих категорій Міжнародної класифікації функціонування, обмежень життєдіяльності та здоров'я (МКФ) для оцінки ефективності реабілітації.

Матеріал і методи: у дослідженні брали участь 17 пацієнтів у віці від 28 до 50 років. Було виділено контрольну групу (КГ) - 9 осіб (4 жінки, 5 чоловіків) та основну(ОГ) - 8 осіб (3 жінки, 5 чоловіків). У пацієнтів ОГ програма фізичної терапії поряд із загальноприйнятими зараз засобами включала ультразвукову терапію з негайними наступними мобілізаційними техніками для ліктьового суглоба. За даними літератури, були визначені оціночні шкали категорій МКФ: гоніометрія, мануальне м'язове тестування, опитувальники Quick Disability of the Arm, Shoulder and Hand Outcome Measure (QuickDASH), Patient-rated elbow evaluation (PREE).

Результати: з базового набору МКФ для станів рук було виділено 8 категорій, що були значимими для пацієнтів та встановлено відповідні оцінки категорій за шкалами. Після проведення фізичної терапії у пацієнтів ОГ оцінки

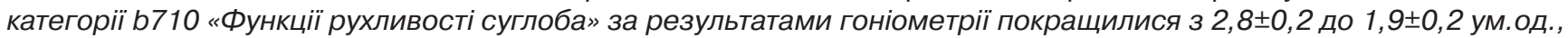

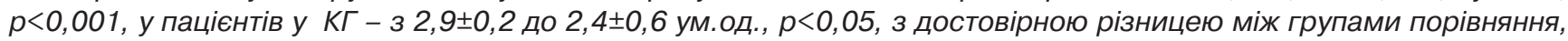
$p<0,05$. Також оцінки категорії d445 «Використання кисті та руки» за шкалою функцій РREЕ у пацієнтів ОГ мали по-

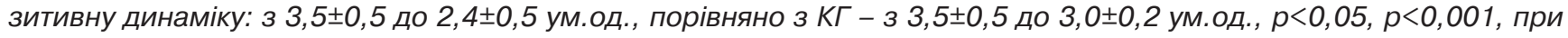
достовірній різниці між показниками ОГ та КГ, $p<0,05$. Середня тривалість пізнього післяопераційного періоду у

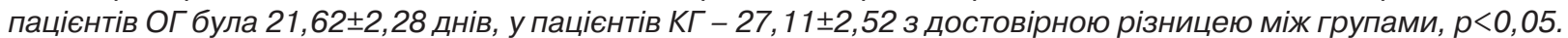

Висновки: визначені найбільш значимі категорії МКФ для контрактури ліктьового суглоба, їх оціночні шкали. На підставі достовірних відмінностей за оцінками двох категорій МКФ (b710 «Функції рухливості суглоба», d445 «Використання кисті та руки», $p<0,05)$ та скороченням тривалості періоду реабілітації $(p<0,05)$ були доведені переваги розробленої програми фізичної терапії.

Ключові слова: посттравматична контрактура ліктьового суглоба, фізична терапія.

\section{Вступ}

Переломи в ділянці ліктьового суглоба (ЛС) становлять 5 - 6\% в структурі ушкоджень скелета, проте частота посттравматичних контрактур ліктьового суглобу (ПТКЛС) та терапія ускладнень після хірургічного втручання з приводу травми ліктя дотепер не визначена $[2,5,11]$. Дослідження довели, що незадовільні результати лікування викликають 33-44\% випадків ПТКЛС, а повторні хірургічні втручання потрібні у 26-55\% пацієнтів [1, 6, 9, 31]. Таким чином, відносно високий рівень ПТКЛС, середній вік пацієнтів (переважно від 45 років), може негативно вразити значну частину активної популяції пацієнтів [8, 22, 25].

Найкращий протокол фізичної терапії (ФТ) при ПТКЛС на основі доказів для пацієнтів після оперативного втручання на сьогодні невідомий і відрізняється в залежності від втручання, лікарні та країни, крім того немає визначених критеріїв оцінки ефективності реабіліта- ції. Використання МКФ у реабілітації дозволить не тільки уніфікувати поняття виду та ступеня порушення функціонування (обмеження життєдіяльності), але і підвищить якість планування реабілітаційних заходів при складанні індивідуальної програми реабілітації. Нажаль, в базових наборах МКФ для окремих захворювань та травм зазначені категорії оцінювання, але не зазначені конкретні методи дослідження, які повинні для цього використовуватись [10, 24, 30, 31].

У зв'язку з цим розробка та обґрунтування сучасної програми ФТ осіб з ПКЛС із використанням доказових засобів реабілітації і методів оцінки їх ефективності на підставі категорій МКФ за оціночними шкалами є актуальною.

Зв'язок роботи з науковими програмами, планами, темами. Дослідження виконано відповідно до ініціативної теми НДР на 2019-2021рр. «Реабілітаційні технології при патології суглобів та зв'язкового апарату» (номер державної реєстрації 0120U104881). 
Метою дослідження було розробити та обґрунтувати сучасну програму ФТ осіб з ПТКЛС у пізньому післяопераційному періоді з використанням оціночних шкал для категорій МКФ для оцінки ефективності реабілітації.

\section{Матеріал і методи дослідження}

У дослідженні брали участь 17 пацієнтів у віці від 28 до 50 років, які проходили відновлювальне лікування в медичному оздоровчому центрі «Fortis» (клінічна база ХДАФК). За методикою випадкових чисел було виділено контрольну групу (КГ) - 9 осіб (4 жінки, 5 чоловіків) та основну (ОГ) - 8 осіб (3 жінки, 5 чоловіків). Критеріями включення були: дуга згинання-розгинання ЛС <100 - або контрактура $>30^{\circ}$ в порівнянні зі здоровою кінцівкою, в анамнезі травма ЛС з оперативним лікуванням 3 заднім доступом до ЛС, іммобілізація задньою гіпсовою лонгетою 3-4 тижні, інформована письмова згода. Критерії виключення: нестабільність ЛС, політравми, неможливість відновлення руху за даними післяопераційної рентгенографії, запалювальні захворювання ЛС. За загальними характеристиками ОГ та КГ були однорідні

Розроблена програма ФТ поряд із загальноприйнятими зараз кінезотерапією (активно-пасивні вправи для підвищення діапазону руху, розтягування, постізометрична релаксація м'язів, техніки пропріоцептивно-нейромязової фасилітації, легкі силові вправи для м'язів, що оточують ЛС, мобілізація лопатки та вправи для її стабілізаторів, вправи для м'язів ротаторної манжети плеча, променево-зап'ястного суглоба та кисті), домашніми вправами для щоденного виконання, носінням нічного статичного ортезу у положенні максимального розгинання суглоба для пацієнтів ОГ включала ультразвукову терапію (УЗТ) з негайними наступними мобілізаційними техніками для ЛС. Пацієнти КГ отримували УЗТ з лікувальним масажем плеча та передпліччя [3, 16, 33].

Ультразвук 3 МГц («Біомед») застосовували до передньої та задньої поверхні ЛС по 3 хв. на поле при 1,4 Вт / см2. Режим безперервний, методика лабільна, контактна (спеціальний гель), через день, 8 процедур. Потім негайно проводилися суглобові мобілізації ЛС (ОГ) або масаж плеча та передпліччя (КГ) протягом 15-20 хвилин $[15,33]$.

Мобілізацію дозували залежно від оцінок пацієнтів. Пацієнти суб'єктивно визначали рівень терпимого болю та оцінювали тиск, крім того, враховували захисну тканинну реакцію, м'язовий спазм та скорочення м'язів. На пізньому післяопераційному етапі використовували мобілізацію за Мейтлендом III-го та IV-го ступеню [4].

Для поліпшення згинання були проведені такі мобілізації суглобів: дистракція, переднє ковзання. Для поліпшення розгинання - дистальне радіальне ковзання. Кожну стійку або коливальну мобілізацію проводили мінімум 30 секунд з 3 повтореннями [33].

За даними літератури, були визначені суб'єктивні та об'єктивні оціночні шкали: гоніометрія [4], мануальне м'язове тестування [18], швидка шкала вимірювання обмежень плеча, руки та кисті (Quick Disability of the Arm, Shoulder and Hand Outcome Measure (QuickDASH)) $[10,29]$, оцінка пацієнтом функціонування ліктьового суглоба (Patient-rated elbow evaluation (PREE)) [27, 28], які використовували для оцінки ефективності реабілітації та ступеню порушення функцій, активності та участі за МКФ.

Методи математичної статистики. Для загальної характеристики показників використовували описову статистику. Розрахунок середньої тривалості пізнього післяопераційного періоду проводився з моменту встановлення діагнозу контрактура (5-8 тижнів після оперативного втручання) та до досягнення діапазону згинання - розгинання ЛС від $30^{\circ}$ до $130^{\circ}$. Для тестування відмінності між групами у динаміці внаслідок невеликої кількості спостережень використовували непараметричну статистику, для пов'язаних сукупностей критерій Вілкоксона, для незалежних Манна-Уітні. Значення $\mathrm{p}<0,05$ вважали значущими. Статистичний аналіз проводився за допомогою статистичної комп'ютерної програми SPSS, версія 16.0 [21].

\section{Результати дослідження}

За результатами дослідження, було обрано з короткого базового набору МКФ для станів верхніх кінцівок категорії, які були притаманні для пацієнтів з ПКЛС, а саме: функції організму (b280 Відчуття болю, b710 Функції рухливості суглоба, b730 Функції м'язової сили) та активність та участь (d520 Догляд за частинами тіла, d550 Вживання їжі, d430 Підняття і перенесення об'єктів, d445 Використання кисті та руки, d850 Оплачувана робота). Серед пацієнтів, які брали участь у дослідженні, усі опитувані мали скарги на b710 Функції рухливості суглоба, b730 Функції м'язової сили, d430 Підняття i перенесення об'єктів, d445 Використання кисті та руки, $52,94 \pm 12,48 \%$ відзначили наявність категорії b280 Від-

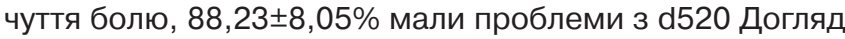

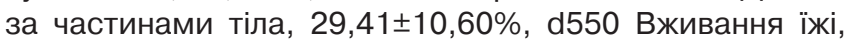
$76,47 \pm 10,60 \%$ - d850 Оплачувана робота. Інші категорії з базового набору не були значущими для осіб з ОГ та КГ, жодна людина не ідентифікувала ці порушення. Кожна 3 категорій була оцінена за відповідною шкалою (табл. 1.).

Метою реабілітації пацієнтів при ПКЛС за МКФ є відновлення: функції оперованого ЛС (на рівні структури), можливості самообслуговування (на рівні активності), професійної активності (на рівні участі). У динаміці через чотири тижні дослідження проводилася оцінка ефективності пізнього післяопераційного періоду за результатами досягнення цілей та завдань реабілітації (табл. 2-3). Меті «Відновити функції руки» відповідало 4-ри категорії МКФ, 2-і з яких достовірно покращились: b710 Функції рухливості суглоба та d445 Використання кисті та руки $(p<0,05)$.

Меті «Забезпечити самодостатність у повсякденному житті» відповідали три категорії МКФ, дві з яких зазнали позитивних змін у обох групах порівняння (табл.3.).

Мета «Повернутись до роботи» $€$ похідною для участі людини у суспільному житті і $€$ найважливішою для реабілітації людини. Категорія d850 Оплачувана робота значно покращилась за досліджуваний період в обох групах $(p<0,05)$, але без істотної різниці між ними (табл. 4.).

Крім того середня тривалість пізнього післяопераційного періоду відновлення у пацієнтів ОГ була $21,62 \pm 2,28$ днів $(9,75 \pm 0,75$ занять кінезотерапії та $7,0 \pm 1,0$ втручань УЗТ плюс мобілізація суглоба), у пацієнтів КГ 27,11 2,52 дня $(11,88 \pm 1,06$ занять кінезотерапії та 7,6 $\pm 0,69$ УЗТ плюс масаж кінцівки) при достовірності різниці між тривалістю періоду фізичної терапії, $p<0,05$.

\section{Висновки / Дискусія}

Класифікація МКФ включає понад 1400 категорій, що обмежують її використання в клінічній практиці [20, 31]. Базові набори МКФ можуть слугувати опорною схе- 
Оціночні шкали для категорій МКФ в залежності від мети реабілітації

\begin{tabular}{|c|c|c|}
\hline Ціль & Категорії МКФ & Інструмент виміру \\
\hline \multirow[t]{4}{*}{$\begin{array}{l}\text { Відновити } \\
\text { функції руки }\end{array}$} & b280 Відчуття болю & $\begin{array}{l}\text { Шкала PREE (біль) } \\
\text { 50-39 балів (4-абсолютні проблеми); } \\
38 \text {-26 балів (3 -важкі проблеми); } \\
25 \text {-13 балів (2 -помірні проблеми;); } \\
1-12 \text { балів( } 1 \text {-легкі проблеми); } \\
0 \text { балів (0 -немає проблем). }\end{array}$ \\
\hline & $\begin{array}{l}\text { b710 Функції } \\
\text { рухливості суглоба }\end{array}$ & $\begin{array}{l}\text { Гоніометрія (4 ступені згинально-розгинальної } \\
\text { контрактури) }\end{array}$ \\
\hline & $\begin{array}{l}\text { b730 Функції } \\
\text { м'язової сили }\end{array}$ & $\begin{array}{l}\text { Мануально-м’язове тестування } \\
\text { 0= повна відсутність напруження м'язів (4-абсолютні } \\
\text { проблеми); } \\
1 \text { = сліди напруження, тобто напруження без руху (4- } \\
\text { абсолютні проблеми); } \\
2 \text { = виразне напруження м'язів і здатність виконати рух } \\
\text { без допомоги, без сили тяжіння (3 -важкі проблеми); } \\
3 \text { = повна амплітуда руху проти сили тяжіння (2 - } \\
\text { помірні проблеми); } \\
4=\text { повна амплітуда руху з середнім опором за всією } \\
\text { амплітудою(1 -легкі проблеми); } \\
5=\text { повна амплітуда з максимальним опором (0 -немає } \\
\text { проблем). }\end{array}$ \\
\hline & $\begin{array}{l}\text { d445 Використання } \\
\text { кисті та руки }\end{array}$ & $\begin{array}{l}\text { Шкала РREE (функціï) } \\
\text { - 50-39 балів (4-абсолютні проблеми); } \\
\text { - } 38 \text {-26 балів (3 -важкі проблеми); } \\
\text { - } 25 \text {-13 балів (2 -помірні проблеми;); } \\
\text { - 1-12 балів }(1 \text {-легкі проблеми); } \\
\text { - } 0 \text { балів (0-немає проблем). }\end{array}$ \\
\hline $\begin{array}{l}\text { Забезпечити } \\
\text { самодостатність у } \\
\text { повсякденному } \\
\text { житті }\end{array}$ & $\begin{array}{l}\text { d520 Догляд за } \\
\text { частинами тіла } \\
\text { d550 Вживання їжі } \\
\text { d430 Підняття i } \\
\text { перенесення об'єктів }\end{array}$ & $\begin{array}{l}\text { QuickDASH } \\
\text { - 100-74 \% (4-абсолютні проблеми); } \\
\text { - } 75 \text {-49 \% (3 -важкі проблеми); } \\
\text { - } 50 \text {-26 \% (2 -помірні проблеми;); } \\
\text { - 1-25\%(1 -легкі проблеми); } \\
\text { • } 0 \text { \% (0 -немає проблем). }\end{array}$ \\
\hline $\begin{array}{l}\text { Повернугись до } \\
\text { роботи }\end{array}$ & $\begin{array}{l}\text { d850 Оплачувана } \\
\text { робота }\end{array}$ & $\begin{array}{l}\text { QuickDASH (додатковий розділ) } \\
\text { - 100-74 \% (4-абсолютні проблеми); } \\
\text { - } 75 \text {-49 \% (3 -важкі проблеми); } \\
\text { - } 50 \text {-26 \% (2 -помірні проблеми;); } \\
\text { - 1-25\%(1 -легкі проблеми); } \\
\text { • } 0 \text { \% (0 -немає проблем). }\end{array}$ \\
\hline
\end{tabular}


Таблиця 2

Оцінка виконання поставленої мети «Відновити функції руки» у пізньому післяопераційному періоді у пацієнтів з ПКЛС груп порівняння

\begin{tabular}{|c|c|c|c|c|c|}
\hline \multirow[t]{2}{*}{$\begin{array}{l}\text { Оціночні шкали та } \\
\text { категорії МКФ }\end{array}$} & \multicolumn{2}{|c|}{$\begin{array}{c}\mathrm{O} \Gamma, \mathrm{M} \pm \mathrm{m} \\
(\mathrm{n}=8)\end{array}$} & \multicolumn{2}{|c|}{$\begin{array}{c}\mathrm{K} \Gamma, \mathrm{M} \pm \mathrm{m} \\
(\mathrm{n}=9)\end{array}$} & \multirow{2}{*}{$\begin{array}{c}\text { р між } \\
\text { групами } \\
\text { порівняння }\end{array}$} \\
\hline & На початку & $\begin{array}{l}\text { Через 4-ри } \\
\text { тижні }\end{array}$ & На початку & $\begin{array}{l}\text { Через 4-ри } \\
\text { тижні }\end{array}$ & \\
\hline $\begin{array}{l}\text { Шкала PREE (біль), } \\
\text { ум.од. }\end{array}$ & $23,0 \pm 6,0$ & $20,25 \pm 7,1$ & $23,2 \pm 5,5$ & $20,5 \pm 5,9$ & $>0,05$ \\
\hline $\begin{array}{l}\text { b280 Відчуття болю, } \\
\text { ум.од. }\end{array}$ & $2,2 \pm 0,5$ & $1,7 \pm 0,6$ & $2,2 \pm 0,6$ & $1,8 \pm 0,9$ & $>0,05$ \\
\hline $\begin{array}{l}\text { Гоніометрія } \\
\text { (розгинання), ум.од. }\end{array}$ & $\begin{array}{l}96,25 \pm \\
6,25\end{array}$ & $\begin{array}{l}143,75 \pm \\
12,18 * *\end{array}$ & $\begin{array}{c}95,55 \pm \\
6,17\end{array}$ & $\begin{array}{c}110,00 \pm \\
8,89 *\end{array}$ & $<0,05$ \\
\hline $\begin{array}{l}\text { Гоніометрія } \\
\text { (згинання), ум.од. }\end{array}$ & $\begin{array}{c}86,25 \pm \\
5,35\end{array}$ & $\begin{array}{l}45,55 \pm \\
4,01 * *\end{array}$ & $\begin{array}{c}85,26 \pm \\
5,11\end{array}$ & $\begin{array}{l}61,12 \pm \\
4,87^{*}\end{array}$ & $<0,05$ \\
\hline $\begin{array}{l}\text { Гоніометрія } \\
\text { (пронація), ум.од. }\end{array}$ & $\begin{array}{c}16,21 \pm \\
1,13\end{array}$ & $\begin{array}{l}50,15 \pm \\
6,17 * *\end{array}$ & $\begin{array}{c}15,33 \pm \\
1,27\end{array}$ & $\begin{array}{l}30,15 \pm \\
3,49 *\end{array}$ & $<0,05$ \\
\hline $\begin{array}{l}\text { Гоніометрія } \\
\text { (супінація), ум.од. }\end{array}$ & $\begin{array}{c}10,23 \pm \\
1,24 \\
\end{array}$ & $\begin{array}{l}43,75 \pm \\
3,44 * *\end{array}$ & $\begin{array}{c}11,33 \pm \\
1,11\end{array}$ & $\begin{array}{c}25,45 \pm \\
2,81 *\end{array}$ & $<0,05$ \\
\hline $\begin{array}{l}\text { b710 Функції } \\
\text { рухливості суглоба, } \\
\text { ум.од. }\end{array}$ & $2,8 \pm 0,2$ & $1,9 \pm 0,2 * *$ & $2,9 \pm 0,2$ & $2,4 \pm 0,6^{*}$ & $<0,05$ \\
\hline $\begin{array}{l}\text { ММТ згинання, } \\
\text { ум.од. }\end{array}$ & $4,0 \pm 0,2$ & $4,1 \pm 0,2$ & $3,8 \pm 0,5$ & $3,9 \pm 0,6$ & $>0,05$ \\
\hline $\begin{array}{l}\text { ММТ розгинання, } \\
\text { ум.од. }\end{array}$ & $3,1 \pm 0,4$ & $3,4 \pm 0,6$ & $3,2 \pm 0,5$ & $3,3 \pm 0,4$ & $>0,05$ \\
\hline $\begin{array}{l}\text { b730 Функції м'язової } \\
\text { сили, ум.од. }\end{array}$ & $3,1 \pm 0,4$ & $3,4 \pm 0,5$ & $3,1 \pm 0,4$ & $3,2 \pm 0,3$ & $>0,05$ \\
\hline $\begin{array}{l}\text { Шкала PREE } \\
\text { (функції), ум.од. }\end{array}$ & $\begin{array}{c}37,75 \pm \\
2,87 \\
\end{array}$ & $\begin{array}{l}25,37 \pm \\
3,47 * * \\
\end{array}$ & $\begin{array}{c}37,89 \pm \\
4,81 \\
\end{array}$ & $\begin{array}{c}32,22 \pm \\
5,48^{*} \\
\end{array}$ & $<0,05$ \\
\hline $\begin{array}{l}\text { d445 Використання } \\
\text { кисті та руки, ум.од. }\end{array}$ & $3,5 \pm 0,5$ & $2,4 \pm 0,5^{* *}$ & $3,5 \pm 0,5$ & $3,0 \pm 0,2^{*}$ & $<0,05$ \\
\hline
\end{tabular}

* - достовірна різниця між показниками пов'язаних вибірок у динаміці, $p<0,05$;

** - достовірна різниця між показниками пов'язаних вибірок у динаміці, $p<0,001$

мою та практичним інструментом для ефективної класифікації та опису функціонування пацієнта. Базові набори МКФ містять якнайменше категорій, проте стільки, скільки необхідно для опису рівня функціонування пацієнта. 117 категорій МКФ було обрано для включення до Комплексного ядра МКФ щодо станів верхніх кінцівок. 3 базового короткого набору МКФ для умов рук (23 категорії) за результатами опитування було виділено тільки 8 категорій, які найчастіше є значимими для пацієнтів 3 контрактурами ЛС.

Для характеристики категорій можна використовувати гоніометрію (4-ри ступені контрактури ЛС) [4], ММТ (за 6-ти бальною шкалою) [18], шкали QuickDASH (має 5 градацій) та PREE, який рекомендують як валідний для використання оцінки категорій МКФ [28].

На підставі вивчення літератури [12, 13, 33] та аналізу функціональних змін при післяопераційній контрактурі разом з використанням найбільш доказових засобів реабілітації при ПКЛС до програми ФТ у пізньому післяопераційному періоді було включено УЗТ з наступними мобілізаційними техніками. Саме мобілізаційні техніки м'яких тканин мають такі ефекти: пригнічення болю, поліпшення кровопостачання, поліпшення мобільності, запуск протизапальних процесів, загоєння тканин. Клінічно рубцева тканина та фіброз викликають біль, спазм м'язів та контрактуру суглобів. Збільшення еластичнос- 
Таблиця 3

Оцінка виконання поставленої мети “Забезпечити самодостатність у повсякденному житті» у пізньому післяопераційному періоді у пацієнтів з ПКЛС груп порівняння

\begin{tabular}{|c|c|c|c|c|c|}
\hline \multirow[t]{2}{*}{$\begin{array}{l}\text { Оціночні шкали та } \\
\text { категорії МКФ }\end{array}$} & \multicolumn{2}{|c|}{$\begin{array}{c}\mathrm{O} \Gamma, \mathrm{M} \pm \mathrm{m} \\
(\mathrm{n}=8)\end{array}$} & \multicolumn{2}{|c|}{$\begin{array}{c}\mathrm{K} \Gamma, \mathrm{M} \pm \mathrm{m} \\
(\mathrm{n}=9)\end{array}$} & \multirow[t]{2}{*}{$\begin{array}{c}\text { p між групами } \\
\text { порівняння }\end{array}$} \\
\hline & $\begin{array}{c}\text { На } \\
\text { початку }\end{array}$ & $\begin{array}{l}\text { Через 4-ри } \\
\text { тижні }\end{array}$ & $\begin{array}{c}\text { На } \\
\text { початку }\end{array}$ & $\begin{array}{c}\text { Через 4-ри } \\
\text { тижні }\end{array}$ & \\
\hline QuickDASH, \% & $62,2 \pm 2,5$ & $56,8 \pm 5,0$ & $58,3 \pm 5,1$ & $55,4 \pm 4,7$ & $>0,05$ \\
\hline $\begin{array}{l}\text { d520 Догляд за } \\
\text { частинами тіла, ум.од }\end{array}$ & $4,3 \pm 0,6$ & $2,4 \pm 0,7 *$ & $4,1 \pm 0,8$ & $2,5 \pm 0,7 *$ & $>0,05$ \\
\hline $\begin{array}{l}\text { d550 Вживання їжі, } \\
\text { ум.од }\end{array}$ & $2,2 \pm 0,6$ & $1,5 \pm 0,5^{*}$ & $2,2 \pm 0,7$ & $1,4 \pm 0,5 *$ & $>0,05$ \\
\hline $\begin{array}{l}\text { d430 Підняття i } \\
\text { перенесення об'єктів, } \\
\text { ум.од }\end{array}$ & $3,6 \pm 0,9$ & $3,2 \pm 0,6$ & $4,1 \pm 0,4$ & $3,4 \pm 0,4$ & $>0,05$ \\
\hline
\end{tabular}

* - достовірна різниця між показниками пов'язаних вибірок у динаміці, p<0,05

Таблиця 4

Оцінка виконання поставленої мети «Повернутись до роботи» у пізньому післяопераційному періоді у пацієнтів з ПКЛС груп порівняння

\begin{tabular}{|c|c|c|c|c|c|}
\hline \multirow[t]{2}{*}{$\begin{array}{l}\text { Оціночні шкали та } \\
\text { категорії МКФ }\end{array}$} & \multicolumn{2}{|c|}{$\begin{array}{c}\mathrm{O} \Gamma, \mathrm{M} \pm \mathrm{m} \\
(\mathrm{n}=8)\end{array}$} & \multicolumn{2}{|c|}{$\begin{array}{c}\mathrm{K} \Gamma, M \pm m \\
(\mathrm{n}=9)\end{array}$} & \multirow{2}{*}{$\begin{array}{l}\text { р між } \\
\text { групами } \\
\text { порівняння }\end{array}$} \\
\hline & $\begin{array}{l}\text { На } \\
\text { початку }\end{array}$ & Через 4-ри тижні & $\begin{array}{l}\text { На } \\
\text { початку }\end{array}$ & $\begin{array}{l}\text { Через 4-ри } \\
\text { тижні }\end{array}$ & \\
\hline $\begin{array}{l}\text { QuickDASH } \\
\text { (додатковий розділ), \% }\end{array}$ & $67,9 \pm 18,1$ & $50,0 \pm 12,5^{*}$ & $72,9 \pm 15,2$ & $46,9 \pm 13,4 *$ & $>0,05$ \\
\hline $\begin{array}{l}\text { d850 Оплачувана } \\
\text { робота, ум.од. }\end{array}$ & $3,00 \pm 0,75$ & $2,25 \pm 0,62$ & $3,22 \pm 0,69$ & $2,12 \pm 0,74 *$ & $>0,05$ \\
\hline
\end{tabular}

* - достовірна різниця між показниками пов'язаних вибірок у динаміці, $p<0,05$

ті та розтяжності тканин, що виникає при використанні УЗТ, що зменшує рубцювання тканин та фіброз, призводить до збільшення діапазону рухів та зменшення болю, а отже, це є клінічно важливим.

Отримані у роботі результати узгоджуються з результатами інших досліджень. Було доведено можливість використання з точки зору доказового терапевтичного впливу УЗТ на біль, спазм м'язів та контрактуру інших суглобів $[7,13,26]$. Крім того, звертали увагу результати наукових публікацій $[13,19]$ про ефективне застосування лікувальних вправ, таких як вправи для підвищення діапазону руху у 20-хвилинному вікні після застосування УЗТ, оскільки в цьому вікні були показані сприятливі фізіологічні результати. Також поєднання УЗТ з мобілізацією суглобів було ефективним при посттравматичній контрактурі суглобів верхніх кінцівок за результатами дослідження серії випадків [13]. Мобілізацію суглобів проводили відразу після ультразвукової обробки, оскільки тепло швидко розсіюється через теплопро- відність від ділянки через судинну систему. Підвищення температури скелетних м'язів швидко зменшується протягом перших 10-15 хвилин після завершення УЗТ $[19,23]$. Ф. Калтенборн [17] вважав, що у гіпомобільному суглобі при мобілізації отримується більший діапазон рухів, ніж при базовій розтяжці. Розтягування спрацьовує лише на кутові компоненти (тобто згинання, розгинання), тоді як спільна мобілізація працює на допоміжні компоненти, найважливішими з яких є ковзання. Калтенборн створив теорію, згідно якої повна амплітуда пасивного руху у синовіальному суглобі є можливою лише при наявності так званих додаткових суглобових рухів: ковзання, обертання, витягання, стискання. Це нефізіологічні малоамплітудні рухи, що перебувають поза вольовим контролем пацієнта можуть бути виконані тільки фізичним терапевтом $[12,15]$.

Показаннями до мобілізації суглобів є біль, м'язовий спазм, блокада, оборотна гіпомобільність суглобів та функціональна контрактура. 
Таким чином, визначені найбільш значимі категорії МКФ для контрактури ЛС, їх оціночні шкали. На підставі оціночних шкал та оцінки категорій МКФ було доведено переваги включення УЗТ з негайною мобілізацією ЛС у програму фізичної терапії за достовірними відмінностями за двома категоріями МКФ (b710 Функції рухливос- ті суглоба, d445 Використання кисті та руки, $p<0,05)$ та скороченням тривалості періоду реабілітації $(p<0,05)$.

Перспективи подальших досліджень у даному напрямку полягають у тому, що отримані результати мають ефект у достатньо короткому часовому інтервалі і потребують більш довготривалої перевірки.

Конфлікт інтересів. Автори заявляють, що немає конфлікту інтересів, який може сприйматися як такий, що може завдати шкоди неупередженості статті.

Джерела фінансування. Ця стаття не отримала фінансової підтримки від державної, громадської або комерційної організації.

\section{Список посилань}

1. Без'язична О. В. (2015), Комплексна фізична реабілітація після внутрішньосуглобових переломів ліктьового суглоба: метод. рекомендації. Харків, $47 \mathrm{c}$.

2. Бур'янов О. А., Кваша В. П., Солов'єв І. О., Ковальчук Д. Ю., Чекушин Д. А. (2018), «Профілактика, лікування і реабілітація післятравматичних і післяопераційних контрактур ліктьового суглобу", Літопис травматології та ортопедії, №3-4, С. 39-40.

3. Вакуленко Л. О., Прилуцький 3. П., Вакуленко Д. В., Кутаков С. В., Лучишин Н. Ю. (2013), Основи масажу. Тернопіль: ТНПУ, 132 с.

4. Герцик А. (2018), Теоретико-методичні основи фізичної реабілітації / фізичної терапії при порушеннях діяльності опорно-рухового апарату: монографія. Львів: ЛДУФК, 2018. 388 c. URL: http://repository.Idufk.edu.ua/handle/34606048/19677

5. Доманський А. М., Лоскутов О. Є. Хом'яков В. М. (2020), «Причини формування інвалідності внаслідок травм ліктьового суглоба», Патологія, №2(49), С. 222-227.

6. Курінний І. М., Страфун С. О., Долгополов О. В., Герасименко І. М. (2017), «Рухова реабілітація хворих після операції з приводу післятравматичної контрактури ліктьового суглоба», Клінічна хірургія, №11, С. 65-69. URL: http://nbuv.gov.ua/UJRN/KIKh_2017_11_20

7. Молєв В., Михальський А. (2019), «Фізична реабілітація осіб з пошкодженнями ліктьового суглоба», Вісник Кам'янецьПодільського національного університету імені Івана Огієнка. Фізичне виховання, спорт і здоров'я людини, Вип. 15, С. 76-80. URL: http://nbuv.gov.ua/UJRN/Vkpnui_fv_2019_15_17.

8. Підкопай Т. В., Єгоров Б. В. (2016), «Деякі результати застосування програми фізичної реабілітації після переломів ліктьового суглобу», Фізична реабілітація та рекреаційно-оздоровчі технології, №2, С. 71-73.

9. Пустовойт Б. А., Без'язична О. В. (2016), «Лікувальна фізична культура після артроскопічних втручань на ліктьовому суглобі», Фізична реабілітація та рекреаційно-оздоровчі технології, №3, С. 190-194.

10. Страфун О. С. (2019), «Порівняння ряду міжнародних оціночних шкал функції ліктьового суглоба», Вісник ортопедії, травматології та протезування, № 4, С. 44-50. Режим доступу: http://nbuv.gov.ua/UJRN/Votip_2019_4_9.

11. Adolfsson L. (2018), «Post-traumatic stiff elbow», EFORT OpenRev, № 3(5), P. 210-216. doi: 10.1302/2058-5241.3.170062.

12. Cancio J. M., Rhee P. (2018), «Therapeutic Management of the Posttraumatic Stiff Elbow After Open Osteocapsular Release», Tech Hand Up Extrem Surg, № 22(4), P. 134-136. doi: 10.1097/BTH.0000000000000207.

13. Draper D. O. (2010), «Ultrasound and joint mobilizations for achieving normal wrist range of motion after injury or surgery»: a case series [published correction appears in J Athl Train. 2011 Jan-Feb;46(1):112]. J Athl Train, № 45(5), P. 486-491. doi:10.4085/1062-6050-45.5.486

14. Fusaro I., Orsini S., Stignani Kantar S., Sforza T., Benedetti M.G., Bettelli G., Rotini R. (2014), «Elbow rehabilitation in traumatic pathology», Musculoskelet Surg, № 98, P. 95-102. doi: 10.1007/s12306-014-0328-x.

15. Harding P., Rasekaba T., Smirneos L., Holland A. E. (2011), "Early mobilisation for elbow fractures in adults", Cochrane Database of Systematic Reviews, Art. No.: CD008130. DOI: 10.1002/14651858.CD008130.pub2

16. Jones V. (2016), «Conservative management of the post-traumatic stiff elbow: a physiotherapist's perspective», Shoulder Elbow, № 8, P. 134-141.

17. Kaltenborn F. M., Evjenth O. (1989), Mobilization of the extremity joints. Oslo: Olaf Norlis Bokhandel, pp 15-16.

18. Kendall F. (2005), Muscles: Testing and Function, with Posture and Pain. Lippincott Williams \& Wilkins, 480 p.

19. Kim S. E., Choi Y. C., Lee J.Y. (2020), «Early Rehabilitation after Surgical Repair of Medial and Lateral Collateral Elbow Ligaments: A Report of Three Cases», Int J Environ Res Public Health, № 17(17), P. 6133. doi: 10.3390/ijerph17176133.

20. Kus S., Dereskewitz C., Coenen M., Rauch A., Rudolf K. D. (2017), «Consortium Lighthouse Project Hand. International Classification of Functioning, Disability and Health: development of an assessment set to evaluate functioning based on the Brief ICF Core Set for Hand Conditions - ICF Hand", J Hand Surg Eur, № 42(7), P. 731-741. doi: 10.1177/1753193417706248.

21. Landou S., Everitt B.S. (2004), A handbook of statistical analyses using SPSS. Boca Raton, FL: Chapman \& Hall/CRC, 339 p.

22. Masci G., Cazzato G., Milano G., Ciolli G., Malerba G., Perisano C., Greco T, Osvaldo P, Maccauro G, Liuzza F. (2020), «The stiff elbow: Current concepts», OrthopRev (Pavia), №12, P. 8661. doi: 10.4081/or.2020.8661.

23. Mellema J. J., Lindenhovius A. L., Jupiter J. B. (2016), «The posttraumatic stiff elbow: an update», Current Reviews in Musculoskeletal Medicine, № 9(2), P. 190-198. DOI: 10.1007/s12178-016-9336-9.

24. Mittal R. (2017), «Posttraumatic stiff elbow», Indian J Orthop, № 51(1), P. 4-13. doi:10.4103/0019-5413.197514.

25. Patico J. M., Saenz V. P. (2020), «Stiff Elbow», [Updated 2020 Aug 10]. In: StatPearls [Internet]. Treasure Island (FL): StatPearls Publishing, Availablefrom: https://www.ncbi.nlm.nih.gov/books/NBK459268/.

26. Swensen S. J., Tyagi V., Uquillas C. et al. (2019), «Maximizing outcomes in the treatment of radial head fractures», J Orthop Traumatol, № 20, P. 15. URL: https://doi.org/10.1186/s10195-019-0523-5.

27. Vincent J., MacDermid J. C. (2012), «The Patient-Rated Elbow Evaluation (PREE)», J Physiother, № 58(4), P. 274. doi: 10.1016/S1836-9553(12)70134-0. 


\section{СЛОБОЖАНСЬКИЙ НАУКОВО-СПОРТИВНИЙ ВІСНИК}

28. Vincent J. I., MacDermid J. C., King G. J., Grewal R. (2015), «Linking of the Patient Rated Elbow Evaluation (PREE) and the American Shoulder and Elbow Surgeons - Elbow questionnaire (pASES-e) to the International Classification of Functioning Disability and Health (ICF) and Hand Core Sets», J Hand Ther, № 28(1), P. 61-76; quiz 68. doi: 10.1016/j.jht.2014.10.002.

29. Viveen J., Doornberg J. N., Kodde I. F., Goossens P., Koenraadt K.L.M., The B., Eygendaal D. (2017), «Continuous passive motion and physical therapy (CPM) versus physical therapy (PT) versus delayed physical therapy (DPT) after surgical release for elbow contractures; a study protocol for a prospective randomized controlled trial», BMC Musculoskelet Disord, № 18(1), P. 484. doi: 10.1186/ s12891-017-1854-0.

30. Wessel L.E., Gu A., Richardson S.S., Fufa D.T., Osei D.A. (2019), «Elbow contracture following operative fixation of fractures about the elbow», JSES Open Access, № 3(4), P. 261-265. doi: 10.1016/j.jses.2019.09.004.

31. Wilk K. E., Macrina L. C., Cain E. L., Dugas J. R., Andrews J. R. (2012), «Rehabilitation of the Overhead Athlete's Elbow», Sports Health, № 4(5), P. 404-414. doi:10.1177/1941738112455006

32. World Health Organization (2001), ICF - International Classification of Functioning, Disability and Health. Geneva: World Health Organization.

Стаття надійшла до редакції: 15.01.2021 р.

Опубліковано: 22.02.2021 p.

Аннотация. Борис Пустовойт, Святослава Пашкевич, Ольга Безъязычная, Татьяна Парфанюк. Физическая терапия пациентов с посттравматическими контрактурами локтевого сустава. Цель: разработать и обосновать современную программу физической терапии лиц с посттравматическими контрактурами локтевого сустава в позднем послеоперационном периоде с использованием оценочных шкал для отдельных категорий Международной классификации функционирования, ограничений жизнедеятельности и здоровья (МКФ) для оценки эффективности реабилитации. Материал и методы: в исследовании принимали участие 17 пациентов в возрасте от 28 до 50 лет. Были выделены контрольная группа (КГ) - 9 человек (4 женщины, 5 мужчин) и основная (ОГ) - 8 человек (3 женщины, 5 мужчин). У пациентов ОГ программа физической терапии наряду с общепринятыми сейчас средствами включала ультразвуковую терапию с немедленными последующими мобилизационными техниками. По данным литературы, были определены оценочные шкалы категорий МКФ: гониометрия, мануальное мышечное тестирование, опросники Quick Disability of the Arm, Shoulder and Hand Outcome Measure (QuickDASH), Patient-rated elbow evaluation (PREE). Результаты: из базового набора МКФ для состояний рук было выделено 8 категорий, которые чаще всего были значимыми для пациентов с контрактурами локтевого сустава и установлены соответствующие оценки категорий по шкалам. После проведения физической терапии у пациентов ОГ оценки категории b710 «Функции подвижности сустава» по

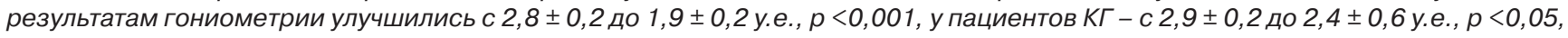
с достоверной разницей между группами сравнения, $p<0,05$. Также оценки категории $d 445$ «Использование кисти и руки» по

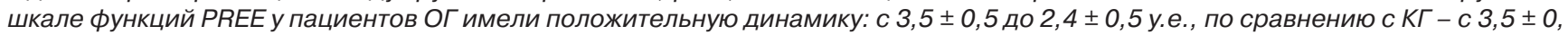
5 до 3,0 0 0,2 у.е., $p<0,05, p<0,001$, при достоверной разнице между ОГ и КГ, $p<0,05$. Средняя продолжительность позднего послеоперационного периода восстановления у пациеентов ОГ была 21,62 +2,28 дней, у пациентов КГ - 27, $11 \pm 2,52$ дня при достоверной разнице между группами, $p<0,05$. Выводы: определены наиболее значимые категории МКФ для контрактуры локтевого сустава, их оценочные шкалы. На основании достоверных различий оценок двух категорий МКФ (b710 «Функции подвижности сустава», $d 445$ «Использование кисти и руки», $p<0,05)$ и сокращением продолжительности периода реабилитации $(p<0,05)$ были доказаны преимущества разработанной программы физической терапии.

Ключевые слова: посттравматическая контрактура локтевого сустава, физическая терапия.

Abstract. Borys Pustovoit, Sviatoslava Pashkevych, Olha Beziazychna, Tetiana Parfaniuk. Physical therapy for patients with posttraumatic elbow contractures. Purpose: to develop and explain a modern program of physical therapy for people with posttraumatic elbow contractures during the late post-operative period using rating scales for the separate categories of International Classification of Functioning, Disability and Health (ICF) to assess the effectiveness of rehabilitation. Material and methods: the study involved 17 patients aged 28 to 50 years. The control group (CG) - 9 people ( 4 women, 5 men) and main group (MG) - 8 people ( 3 women, 5 men) were selected. The program of physical therapy in MG patients included ultrasound therapy with immediate follow-up mobilization techniques for the elbow joint in addition to conventional means. Goniometry, manual muscle testing, questionnaires Quick Disability of the Arm, Shoulder and Hand Outcome Measure (QuickDASH), Patient-rated elbow evaluation (PREE), were defined as rating scales according to literature review. Results: only 8 categories were identified, they were most significant for patients, and the corresponding ratings of the categories were established. After MG patients rehabilitation assessments of category b710 Functions of joint mobility according to the results of goniometry improved from $2.8 \pm 0.2$ to $1.9 \pm 0.2$ c.u., $p<0.001$, for patients of $C G-$ from $2.9 \pm 0.2$ to $2.4 \pm 0.6$ c.u., $p<0.05$, with a significant difference between the comparison groups, $p<0.05$. Also, assessments of category $d 445$ The using of the hand and arm according to the PREE function scale for patients of MG had positive changes: from $3.5 \pm 0.5$ to $2.4 \pm 0.5$ c.u., compared with CG - from $3.5 \pm 0,5$ to $3.0 \pm 0.2$ c.u., $p<0.05, p<0.001$, with a significant difference between MG and CG, $p<0.05$. The average duration of the late postoperative period of the MG was $21.62 \pm 2.28$ days, of the $C G-27.11 \pm 2,52$ days with the difference between groups, $p<0.05$. Conclusions: the most significant categories of IFC for the elbow contracture, their rating scales have been identified. Based on the significant differences of two IFC categories assessments ( $b 710$ Joint mobility functions, $d 445$ Use of hand and arm, $p<0.05$ ) and reducing the duration of the rehabilitation period $(p<0.05)$, the benefits of developed physical therapy program were proved by.

Key words: posttraumatic elbow contracture, physical therapy.

Пустовойт, Б., Пашкевич, С., Без'язична, О., Парфанюк, Т. (2021), «Фізична терапія пацієнтів з посттравматичними контрактурами ліктьового суглоба» 


\section{References}

1. Beziazychna, O. V. (2015), Kompleksna fizychna reabilitatsiya pislia vnutrishniosuhlobovyh perelomiv liktiovoho suhloba [Integrated physical rehabilitation after intra-articular fractures of the elbow joint]: metod. rekomendatsii Kharkiv, 47 p. (in Ukr.).

2. Burianov, O. A., Kvasha, V. P., Soloviev, I. O., Kovalchuk, D. Y., Chekushyn, D. A. (2018), «Prevention, treatment and rehabilitation of post-traumatic and postoperative elbow stiffness», Litopys travmatologii ta ortopedii, No. 3-4, pp. 39-40. (in Ukr.).

3. Vakulenko, L. O., Prylutskyi, Z. P., Vakulenko, D. V., Kutakov, S. V., Luchyshyn, N. Y. (2013), Osnovy masazhu [Basic concepts of massage]. Ternopil: TNPU, 132 p. (in Ukr.).

4. Hertsyk, A. (2018), Teoretyko-metodychni osnovy fizychnoi reabilitatsii/ phisychnoi terapii pry porushenniakh diialnosti opornorukhovoho aparatu [Theoretical and methodical bases of physical rehabilitation / physical therapy for impairments of the musculoskeletal system activity]: monografiia. Lviv: LDUFK, 2018. 388 p. URL: http://repository.Idufk.edu.ua/handle/34606048/19677. (in Ukr.).

5. Domanskyi, A. M., Loskutov, O. Y., Khomiakov, V. M. (2020), «Reasons for the formation of disability due to injuries of the elbow joint», Patologiia, No. 2(49), pp. 222-227. (in Ukr.).

6. Kurinnyi, I. M., Strafun, S. O., Dolhopolov, O. V., Herasymenko, I. M. (2017), «Motor rehabilitation of patients after surgery for post-traumatic elbow joint stiffness", Klinichna khirurgiia, No.11, pp. 65-69. URL: http://nbuv.gov.ua/UJRN/KIKh_2017_11_20. (in Ukr.).

7. Moliev, V., Mykhalskyi, A. (2019), «Physical rehabilitation for people having elbow injuries» [Elektronnyi resurs], Visnyk Kamianets-Podilskoho natsionalnoho universytetu imeni Ivana Ohiyenka. Fizychne vykhovannia, sport, zdorovia liudyny, Vyp. 15, pp. 76-80. URL: http://nbuv.gov.ua/UJRN/Vkpnui_fv_2019_15_17. (in Ukr.).

8. Pidkopai, T.V., Yehorov, B.V. (2016), "Some results of the application of the physical rehabilitation program after fractures of the elbow joint», Fizychna reabilitatsiia ta rekreatsiyno-ozdorovchi tekhnolohii, No.2, pp. 71-73. (in Ukr.).

9. Pustovoit, B. A., Beziazychna, O. V. (2016), «Therapeutic physical culture after arthroscopic interventions on the elbow joint», Fizychna reabilitatsiia ta rekreatsiyno-ozdorovchi tekhnolohii, No.3, pp. 190-194. (in Ukr.).

10. Strafun, O. S. (2019), "Comparison of a number of international elbow joint function rating scales», Visnyk ortopedii, travmatolohii ta protezuvannia, No. 4, pp. 44-50. URL: http://nbuv.gov.ua/UJRN/ Votip_2019_4_9. (in Ukr.). (in Eng.)

11. Adolfsson, L. (2018), «Post-traumatic stiff elbow», EFORT OpenRev, № 3(5), pp. 210-216. doi: 10.1302/2058-5241.3.170062.

12. Cancio, J. M., Rhee, P. (2018), «Therapeutic Management of the Posttraumatic Stiff Elbow After Open Osteocapsular Release», Tech Hand Up Extrem Surg, № 22(4), pp. 134-136 (in Eng.).

13. Draper, D. O. (2010), «Ultrasound and joint mobilizations for achieving normal wrist range of motion after injury or surgery»: a case series [published correction appears in J Athl Train. 2011 Jan-Feb;46(1):112]. J Athl Train, № 45(5), P. 486-491. doi:10.4085/10626050-45.5.486. (in Eng.).

14. Fusaro, I., Orsini, S., Stignani Kantar S., Sforza, T., Benedetti, M.G., Bettelli, G., Rotini, R. (2014), «Elbow rehabilitation in traumatic pathology», Musculoskelet Surg, № 98, P. 95-102. doi: 10.1007/s12306-014-0328-x (in Eng.).

15. Harding, P., Rasekaba, T., Smirneos, L., Holland, A.E. (2011), «Early mobilisation for elbow fractures in adults», Cochrane Database of Systematic Reviews, Art. No.: CD008130. DOI: 10.1002/14651858 (in Eng.).

16. Jones, V. (2016), "Conservative management of the post-traumatic stiff elbow: a physiotherapist's perspective», Shoulder Elbow, № 8, P. 134-141. (in Eng.).

17. Kaltenborn, F.M., Evjenth, O. (1989), Mobilization of the extremity joints. Oslo: Olaf Norlis Bokhandel, pp 15-16. (in Eng.).

18. Kendall, F. (2005), Muscles: Testing and Function, with Posture and Pain. Lippincott Williams \& Wilkins. 480 p. (in Eng.).

19. Kim, S. E., Choi, Y. C., Lee, J. Y. (2020), «Early Rehabilitation after Surgical Repair of Medial and Lateral Collateral Elbow Ligaments: A Report of Three Cases», Int J Environ Res Public Health, № 17(17), P. 6133. doi: 10.3390/ijerph17176133 (in Eng.).

20. Kus, S., Dereskewitz, C., Coenen, M., Rauch, A., Rudolf, K. D. (2017), «Consortium Lighthouse Project Hand. International Classification of Functioning, Disability and Health: development of an assessment set to evaluate functioning based on the Brief ICF Core Set for Hand Conditions - ICF Hand», J Hand Surg Eur, № 42(7), P. 731-741. doi: 10.1177/1753193417706248 (in Eng.).

21. Landou, S. Everitt, B.S. (2004). A handbook of statistical analyses using SPSS. Boca Raton, FL: Chapman \& Hall/CRC, 339 p.

22. Masci, G., Cazzato, G., Milano, G., Ciolli, G., Malerba, G., Perisano, C., Greco, T, Osvaldo, P, Maccauro, G, Liuzza, F. (2020),

«The stiff elbow: Current 16concepts», OrthopRev (Pavia), №12, P. 8661. doi: 10.4081/or.2020.8661 (in Eng.).

23. Mellema, J. J., Lindenhovius, A. L., Jupiter, J. B. (2016), «The posttraumatic stiff elbow: an update», Current Reviews in Musculoskeletal Medicine, № 9(2), P. 190-198. DOI: 10.1007/s12178-016-9336-9. (in Eng.).

24. Mittal, R. (2017), «Posttraumatic stiff elbow», Indian J Orthop, № 51(1), P. 4-13. doi:10.4103/0019-5413.197514. (in Eng.).

25. Patico, J.M., Saenz, V.P. (2020), «Stiff Elbow», [Updated 2020 Aug 10]. In: StatPearls [Internet]. Treasure Island (FL): StatPearls Publishing. URL: https://www.ncbi.nlm.nih.gov/books/NBK459268/ (in Eng.).

26. Swensen, S. J., Tyagi, V., Uquillas, C. et al. (2019), «Maximizing outcomes in the treatment of radial head fractures», J Orthop Traumatol, № 20, P. 15. URL: https://doi.org/10.1186/s10195-019-0523-5. (in Eng.).

27. Vincent, J., MacDermid, J. C. (2012), «The Patient-Rated Elbow Evaluation (PREE)», J Physiother, № 58(4), P. 274. doi: 10.1016/S1836-9553(12)70134-0. (in Eng.).

28. Vincent, J. I., MacDermid, J. C., King, G. J., Grewal, R. (2015), «Linking of the Patient Rated Elbow Evaluation (PREE) and the American Shoulder and Elbow Surgeons - Elbow questionnaire (pASES-e) to the International Classification of Functioning Disability and Health (ICF) and Hand Core Sets», J Hand Ther, № 28(1), P. 61-76; quiz 68. doi: 10.1016/j.jht.2014.10.002. (in Eng.).

29. Viveen, J., Doornberg, J. N., Kodde, I. F., Goossens, P., Koenraadt, K.L.M., The, B., Eygendaal, D. (2017), «Continuous passive motion and physical therapy (CPM) versus physical therapy (PT) versus delayed physical therapy (DPT) after surgical release for elbow contractures; a study protocol for a prospective randomized controlled trial», BMC Musculoskelet Disord, № 18(1), P. 484. doi: 10.1186/s12891-017-1854-0. (in Eng.).

30. Wessel, L. E., Gu, A., Richardson, S. S., Fufa, D. T., Osei, D. A. (2019), «Elbow contracture following operative fixation of fractures about the elbow», JSES Open Access, № 3(4), P. 261-265. doi: 10.1016/j.jses.2019.09.004. (in Eng.).

31. Wilk, K. E., Macrina, L. C., Cain, E. L., Dugas, J. R., Andrews, J. R. (2012), «Rehabilitation of the Overhead Athlete's Elbow», Sports Health, № 4(5), P. 404-414. doi:10.1177/1941738112455006. (in Eng.).

32. World Health Organization (2001), ICF - International Classification of Functioning, Disability and Health. Geneva: World Health Organization. (in Eng.).

Received: 15.01.2021.

Published: 22.02.2021 


\section{СЛОБОЖАНСЬКИЙ НАУКОВО-СПОРТИВНИЙ ВІСНИК}

\section{Відомості про авторів / Information about the Authors}

Пустовойт Борис Анатолійович: д/ мед. наук, професор; Харківська державна академія фізичної культури, вул. Клочківська,99, м. Харків, 61058, Україна.

Пустовойт Борис Анатольевич: д. мед. наук, профессор; Харьковская государственная академия физической культуры: ул. Клочковская, 99, г. Харьков, 61058, Украина.

Borys Pustovoit: Doctor of Science (Medicine), Professor; Kharkiv State Academy of Physical Culture: Klochkivska str. 99, Kharkiv, 61058, Ukraine.

\section{ORCID.ORG/0000-0001-7534-4404}

E-mail: pustovoit203@gmail.com

Пашкевич Святослава Адамівна: канд. мед. наук, доцент; Харківська державна академія фізичної культури: вул. Клочківська,99, м. Харків, 61058, Україна.

Пашкевич Святослава Адамовна: канд. мед. наук, доцент; Харьковская государственная академия физической культуры: ул. Клочковская, 99, г. Харьков, 61058, Украина.

Sviatoslava Pashkevych: candidate of Medical Sciences, Associate Professor; Kharkiv State Academy of Physical Culture: Klochkivska str. 99, Kharkiv,61058, Ukraine.

ORCID.ORG/0000-0002-4842-4350

E-mail: sviatoslava.pashkevych@gmail.com

Без'язична Ольга Володимирівна: старший викладач; Харківська державна академія фізичної культури: вул. Клочківська 99, м. Харків, 61058, Україна.

Безъязычная Ольга Владимировна: старший преподаватель; Харьковская государственная академия физической культуры: ул. Клочковская 99, г. Харьков, 61058, Украина.

Olha Beziazychna: senior lecturer; Kharkiv State Academy of Physical Culture: Klochkivska str. 99, Kharkiv,61058, Ukraine.

ORCID.ORG/0000-0001-9987-6405

E-mail: obezyazychnaya@gmail.com

Парфанюк Тетяна Михайлівна: студентка IV курсу; Харківська державна академія фізичної культури: вул. Клочківська, 99, м. Харків, 61058, Україна.

Парфанюк Татьяна Михайловна: студентка IV курса; Харьковская государственная академия физической культуры, ул. Клочковская, 99, г. Харьков, 61058, Украина.

Tetiana Parfaniuk: student; Kharkiv State Academy of Physical Culture: Klochkivska str. 99, Kharkiv, 61058, Ukraine.

ORCID.ORG/0000-0003-0434-2086

E-mail: t_parf@ukr.net 